\title{
Ra mắt 8 nhóm nghiên cứu mạnh khoa học, công nghệ mũi nhọn
}

Ngày 15-5, tại Hà Nội, Trường Đại học Phenikaa tổ chức lễ công bố quyết định và ra mắt 8 nhóm nghiên cứu mạnh trong các lĩnh vực vật liệu nano trong y sinh, môi trường và năng lượng, hóa dược và hoạt chất sinh học, các hệ thống thông tin thông minh và cảm biến nano, quang tử và quang điện tử, vật lý năng lượng cao và vũ trụ học, và phân tích dữ liệu lưới trong khoa học xã hội.

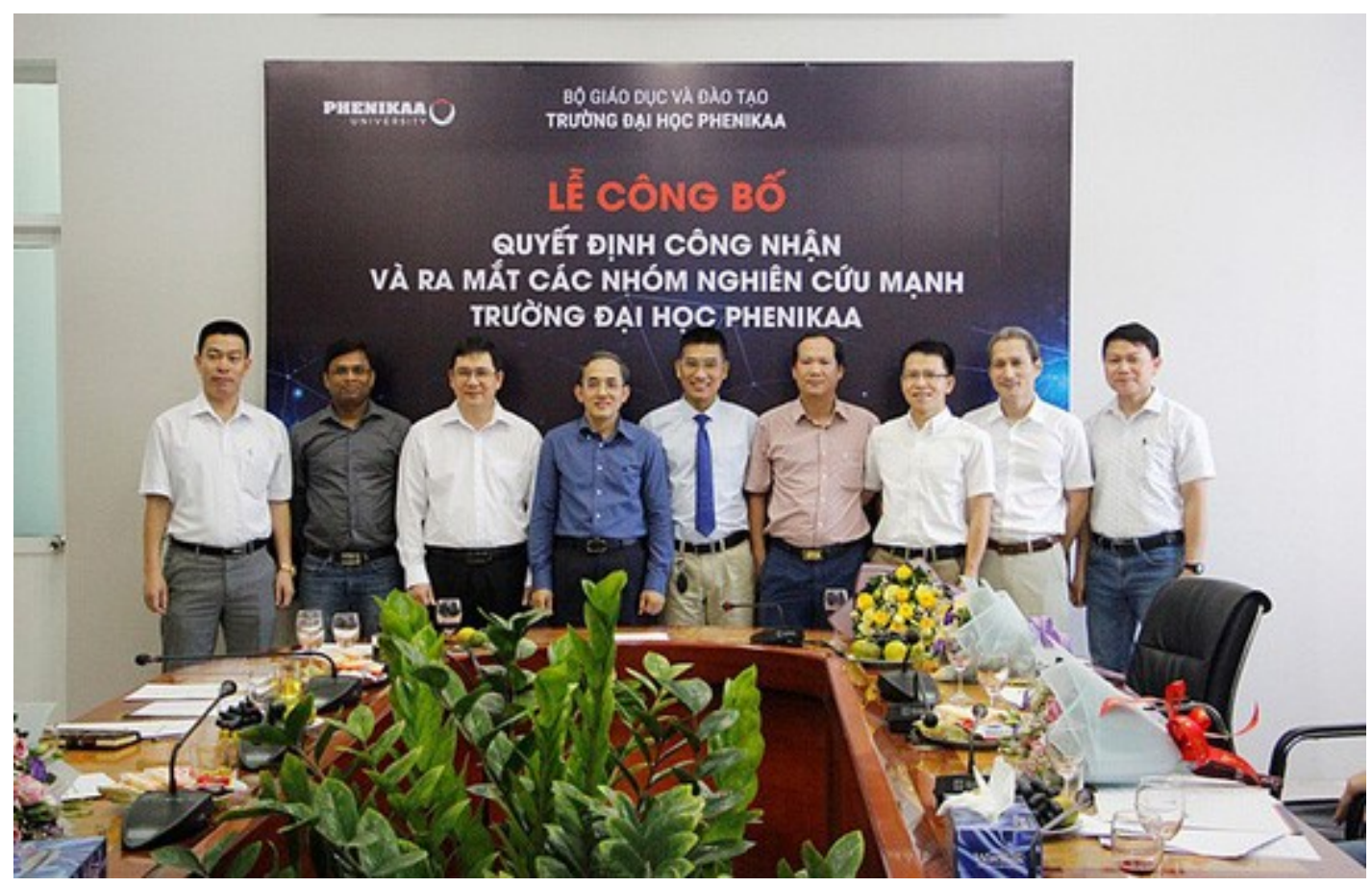

Lễ công bố quyết định và ra mắt 8 nhóm nghiên cứu mạnh Trường Đại học Phenikaa

Các nhóm nghiên cứu mạnh của trường được tuyển chọn thông qua sự đánh giá của hội đồng xét duyệt bao gồm các nhà khoa học như: GS-TS-NGND. Nguyễn Đức Chiến (Trường ĐH Bách Khoa Hà Nội), GS-TS Trần Đại Lâm (Viện Hàn lâm Khoa học và Công nghệ Việt Nam), GS-TS Đào Tiến Khoa (Viện Năng lượng Nguyên tử Việt Nam), GS-TS Mai Thanh Tùng (Trường ĐH Bách Khoa Hà Nội) và GS-TS Nguyễn Hải Nam (Trường ĐH Dược Hà Nội).

8 trưởng nhóm nghiên cứu mạnh được lựa chọn lần này đều là những nhà khoa học đầu ngành với nhiều công bố quốc tế và giàu kinh nghiệm dẫn dắt các nhóm nghiên cứu thành công như: GS-TS Phạm Thành Huy (gương mặt nhà khoa học trẻ tiêu biểu 1.000 năm Thăng Long Hà Nội, năm 2010), GS-TS Nguyễn Văn Hiếu (Giải thưởng Tạ Quang Bửu, năm 2016), PGS-TS Phùng Văn Đồng (Giải thưởng Tạ Quang Bửu dành cho nhà khoa học trẻ, năm 2016), TS Raja Das (JSPS Scholar - Nhật Bản, các năm 2018 và 2019).

Đặc biệt, các nhóm nghiên cứu mạnh của Trường ĐH Phenikaa được phân ra làm 2 loại hình: Nhóm nghiên cứu cơ bản và nhóm nghiên cứu ứng dụng. 


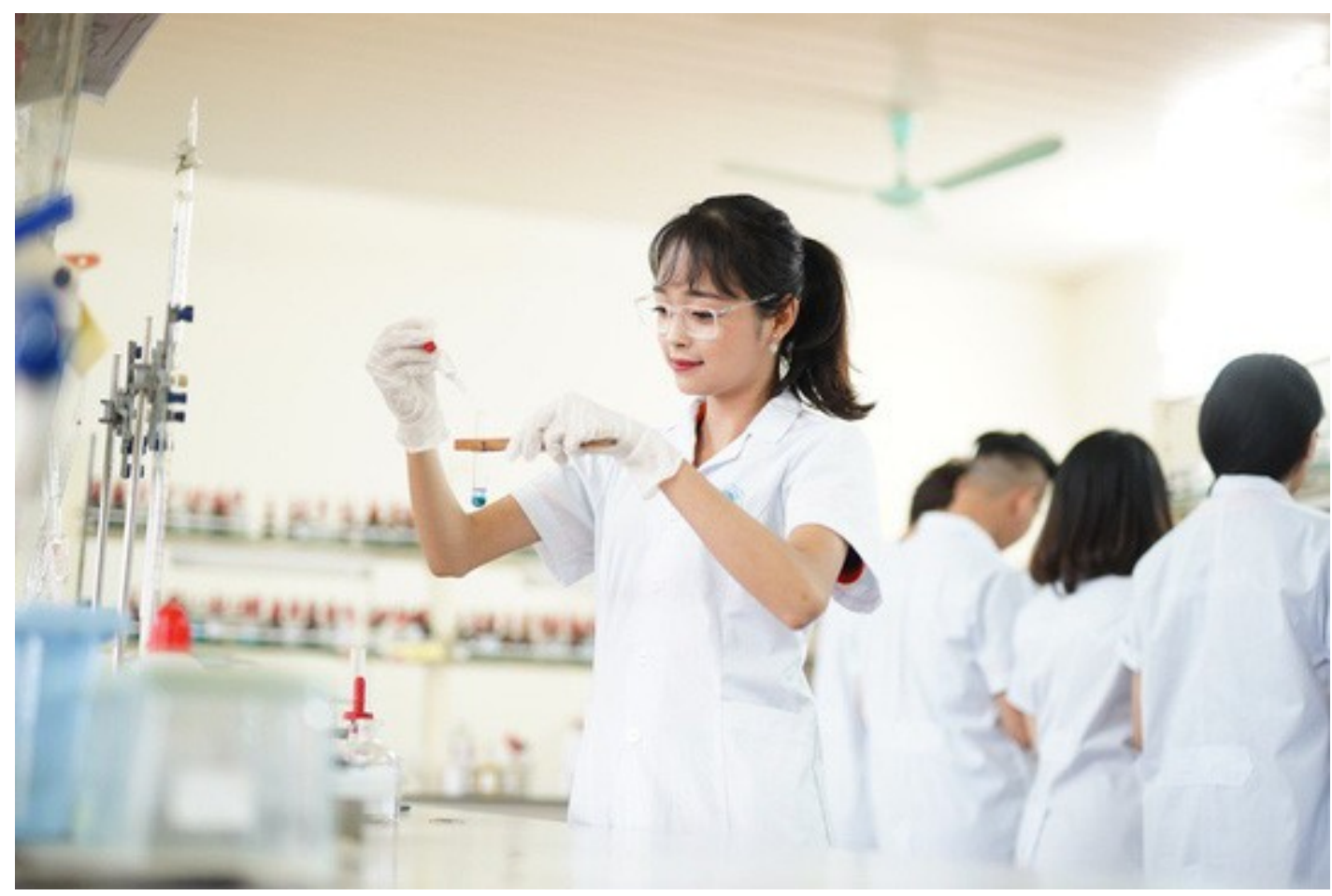

Hoạt động nghiên cứu tại trường ĐH Phenikaa

Trong đợt tuyển chọn năm 2019, có 7 trong tổng số 8 nhóm nghiên cứu mạnh được thành lập là nhóm nghiên cứu cơ bản, trong đó có 6 nhóm nghiên cứu về khoa học tự nhiên và kỹ thuật, công nghệ và 1 nhóm nghiên cứu về khoa học xã hội và nhân văn. Nhóm nghiên cứu duy nhất trong lĩnh vực khoa học xã hội và nhân văn này do TS Vương Quân Hoàng, Giám đốc Trung tâm Nghiên cứu khoa học xã hội liển ngành (ISR) của trường, là người có nhiều công bố quốc tế về lĩnh vực khoa học xã hội, làm trưởng nhóm. Nhóm nghiên cứu ứng dụng đầu tiên tại Trường ĐH Phenikaa là nhóm nghiên cứu quang điện tử và quang tử của GS-TS Phạm Thành Huy - người thường được giới khoa học nhắc tới nhiều trong việc xây dựng mô hình hợp tác nghiên cứu và chuyển giao công nghệ giữa trường ĐH với doanh nghiệp (điển hình là các nghiên cứu ứng dụng thành công tại Công ty Cổ phần Bóng đèn Phích nước Rạng Đông).

Yêu cầu cụ thể đối với nhóm nghiên cứu mạnh trong lĩnh vực nghiên cứu cơ bản là mỗi năm phải công bố ít nhất 5 công trình khoa học là các bài báo trên các tạp chí hạng Q1 (theo tiêu chuẩn của SCImago Journal Rankings), hoặc 8 công trình khoa học trên các tạp chí quốc tế ISI/Scopus, trong đó có ít nhất 3 công trình hạng Q1. Mỗi công trình khoa học hạng Q1 có thể được thay thế bằng một sách chuyên khảo. Đối với nhóm nghiên cứu mạnh trong lĩnh vực nghiên cứu ứng dụng, trong vòng 3 năm phải chuyển giao được ít nhất 1 quy trình công nghệ cho các doanh nghiệp (với tổng kinh phí chuyển giao công nghệ trên 500 triệu đồng), hoặc đăng ký thành công 2 sáng chế/giải pháp hữu ích trong nước hoặc quốc tế.

Mức kinh phí đầu tư cho trang thiết bị nói riêng của mỗi nhóm là 4 tỉ đồng cho 3 năm đầu và kinh phí không hạn chế đối với những nhóm nghiên cứu có mục tiêu phát triển công nghệ ứng dụng. Hoạt động của các nhóm nghiên cứu mạnh sẽ gắn kết chặt chẽ với hoạt động đào tạo và nghiên cứu của các khoa và đặc biệt là 3 viện nghiên cứu của trường: Viện Nghiên cứu Tiên tiến Phenikaa (PIAS - tập trung vào nghiên cứu khoa học cơ bản), Viện Nghiên cứu và Công nghệ Phenikaa (PRATI - tập trung vào khoa học ứng dụng và phát triển công nghệ), Viện Nghiên cứu nano (PHENA - nghiên cứu về vật liệu và công nghệ nano).

Trường ĐH Phenikaa là thành viên của Tập đoàn Phenikaa - một tập đoàn sản xuất công nghiệp về vật liệu sinh thái và sản phẩm công nghệ cao. Hiện tại, Trường có 21 chương trình đào tạo thuộc 4 khối ngành, bao gồm khối ngành khoa học tự nhiên, kỹ thuật và công nghệ, khối ngành sức khỏe, khối ngành kinh tế và khối ngành khoa học xã hội và nhân văn.

D.Châu 